http://jmscr.igmpublication.org/home/ ISSN (e)-2347-176x ISSN (p) 2455-0450

crossref DOI: https://dx.doi.org/10.18535/jmscr/v9i12.40

Journal Of Medical Science And Clinical Research

\title{
Echocardiographic Evaluation of Patients with Chronic Obstructive Pulmonary Disease and Its Correlation with Disease Severity
}

\author{
Authors \\ Dr Jesinkumar.C ${ }^{1}$, Dr Manoj.D.K ${ }^{2}$, Dr Muhammad Shafeek.K ${ }^{3}$, Dr Rajani.M ${ }^{4}$, \\ Dr Padmanabhan.K. $\mathbf{V}^{5}$ \\ ${ }^{1}$ Assistant Professor, Dept of Respiratory Medicine, Karuna Medical College \\ ${ }^{2}$ Professor \& HOD, Dept of Respiratory Medicine, Govt Medical College, Kannur \\ ${ }^{3}$ Assistant Professor, Dept of Respiratory Medicine, Govt Medical College, Kannur. \\ ${ }^{4}$ Professor, Dept of Respiratory Medicine, Govt Medical College, Kannur \\ ${ }^{5}$ Assistant Professor, Dept of Respiratory Medicine, Govt Medical College, Kannur \\ *Corresponding Author \\ Dr Rajani.M \\ Professor, Dept of Respiratory Medicine, Govt Medical College, Kannur, Kerala, India
}

\begin{abstract}
The heart and the respiratory system are closely related anatomically and functionally. Dysfunction of one of these systems can influence the function of the other. Cardiovascular comorbidities are the most common comorbidity found in COPD patients. Objectives of the sudy are to assess the cardiovascular changes secondary to COPD by echocardiography \& to find out the correlation between echocardiographic findings and severity of COPD

Methodology: It was a Hospital based cross-sectional study.Study samples were COPD patients attending the Department of Respiratory medicine during the study period.

Patients were selected according to the inclusion and exclusion criteria Detailed history, general and systemic examination was done.All routine investigations were done as needed. Patients were investigated by spirometry and diagnosed and classified according to GOLD guidelines. Severity of COPD were classified according to GOLD criteria into groups $A, B, C$ or $D$. All patients were subjected to resting two-dimensional transthoracic echocardiography in Department of Cardiology.

Statistical Procedure:_Descriptive statistical tools like frequency, percentage, mean and standard deviation were used. Inferential statistical tools like t test, chi square test and Spearman's correlation coefficient were used.

Results: Total 144 patients were included.120 males and 24 females. Out of these 144 patients, 65 patients had no pulmonary hypertension. 53 had mild PH, 12 had moderate PH and 14 had severe PH. Among the other echo findings, left ventricular diastolic dysfunction (47 patients) was the most common. 7 patients had left ventricular systolic dysfunction and 3 patients had left ventricular hypertrophy.

Conclusion: COPD is associated with numerous cardiovascular co morbidities in the North Malabar area of Kerala. Echo is a portable, non-invasive method and accurate method that can act as a valuable tool in the evaluation of COPD patients.
\end{abstract}

Keywords: Echo Cardiography, COPD, Right Ventricular Function.

\section{Introduction}

COPD is associated with numerous systemic co morbidities. The heart and the respiratory system are closely related anatomically and functionally.
Dysfunction of one of these systems can influence the function of the other ${ }^{(1)}$. Cardiovascular co morbidities are hence the most common comorbidity found in COPD patients. 
The presence of common risk factors like smoking, age, sex and inactivity can in part explain the close association between COPD and cardiovascular diseases ${ }^{(2)}$. Smoking can induce local inflammatory changes throughout the tracheobronchial tree including the large airways proximally, small airways peripherally, lung parenchyma and pulmonary vasculature. It can also stimulate the haematopoetic system causing the release of polymorphonuclear leukocytes. It also contributes to systemic oxidative stress and dysfunction of the endothelium of peripheral vessels. These systemic effects of smoking also account for the presence of cardiovascular disease in COPD patients ${ }^{(3)}$

COPD can affect the pulmonary blood vessels, right ventricle and left ventricle. COPD is the most common pulmonary disease resulting in right ventricular dysfunction ${ }^{(4)}$

Pulmonary hypertension, associated with COPD, is a significant risk factor for hospitalization ${ }^{(5)}$.

Echocardiography is portable, non-invasive and accurate method for evaluating the cardiac status. The right ventricular function, right ventricular filling pressure, left ventricular functioning, valvular function and tricuspid regurgitation can be assessed through echocardiography ${ }^{(6)}$. The pulmonary artery pressures obtained through echocardiography is comparable to the values obtained through right heart catheterization ${ }^{(7,8)}$. It aids in rapid and early detection of cardiac dysfunction and thus help in early initiation of treatment. Early recognition of RV dysfunction and initiation of treatment can prolong the survival of COPD patients as most of the increased mortality associated with COPD is due to cardiac involvement ${ }^{(9)}$. Echo can thus serve as a useful aid to reduce mortality and morbidity associated with COPD.

Left ventricular performance is also affected in patients with severe COPD. This may occur due to the effect of hypoxemia and acidosis on LV relaxation, bulging of the interventricular septum or due to concurrent coronary artery disease. Since it also affects the LV stroke volume, LV filling and cardiac output; corpulmonale can be considered as a generalized cardiomyopathy ${ }^{(10)}$. Studying the cardiovascular co morbidities in COPD is important because of the implications it may have on the management of these patients $^{(11,12)}$. It may also aid in the risk prediction of cardiovascular diseases in patients with COPD.

The present study was done To assess the cardiovascular changes secondary to COPD by echocardiography \& To find out the correlation between echocardiographic findings and severity of COPD.

\section{Methodology}

Study was started after obtaining clearance from the institutional ethical \& research committee. This was a hospital based cross-sectional study. Study period was for one year( $1^{\text {st }}$ March 2016 to $28^{\text {th }}$ February 2017).Study sample were COPD patients attending Department of Respiratory medicine, Pariyaram medical college during the study period.

Sample Size was calculated Using level of significance $5 \%$, allowable error of $5 \%$ and $\mathrm{p}$ of $10 \%{ }^{(85)}$; minimum sample size was calculated as 144 patients.

All Patients diagnosed with COPD through spirometry with post bronchodilator FEV1/FVC < 0.70.(1) were included in the study.

Exclusion Criteria were 1) Patients below 40 years of age, 2) Patients with history of chronic lung disease other than COPD,3)Patients with hypertension,4)Patients with any primary cardiac disease (congenital heart diseases, valvular heart diseases, coronary artery disease),5)Patients with any systemic disease that can cause pulmonary hypertension, 6)Patients with poor ECHO window, 7)patients with history of Recent respiratory tract infection in the preceding six weeks, 8)Patients unable to perform spirometry, 9)Patients who were unwilling.

\section{Study Design}

Patients were selected according to the inclusion and exclusion criteria. Written informed consent was taken from the patients. Detailed history, 
general and systemic examination was done. All routine investigations, including complete blood count, lipid profile, blood sugar, urea, creatinine, electrocardiography and so on were done as needed. Patients were investigated by spirometry and diagnosed and classified according to GOLD guidelines (postbronchodilator $\mathrm{FEV}_{1} / \mathrm{FVC}$ ratio $<70 \%$ of predicated), into mild $\left(\mathrm{FEV}_{1} \geq 80 \%\right.$ of predicted), moderate $\left(50 \% \leq \mathrm{FEV}_{1}<80 \%\right)$, severe $\left(30 \% \leq \mathrm{FEV}_{1}<50 \%\right) .{ }^{(13)}$ Severity of COPD were classified according to GOLD criteria into groups A, B, C or D. ${ }^{(13)}$

All patients were subjected to resting twodimensional transthoracic echocardiography in Department of Cardiology, Pariyaram Medical College Hospital. Echocardiography was reviewed to assess the pericardium, valvular anatomy and function, left and right side chamber size and cardiac function. Patients with pulmonary hypertension (sPAP> $30 \mathrm{mmHg}$ ) were classified into mild (sPAP $=30-50 \mathrm{mmHg}$ ), moderate (sPAP $=50-70 \mathrm{mmHg})$, severe $(\mathrm{sPAP}>70 \mathrm{mmHg})^{(14)}$. Patients requiring active cardiac intervention were referred to the Department of Cardiology.

Statistical Procedure: Descriptive statistical tools like frequency, percentage, mean and standard deviation were used. Inferential statistical tools like $\mathrm{t}$ test, chi square test and Spearman's correlation coefficient were used. A $\mathrm{p}$ value of $<0.05$ was considered significant.

\section{Results}

Total 144 patients were included in this study. The following observations were made from study. The most common age group was 55-65 years. The mean age of the study population was 61 years. Study group showed 120 males and 24 females.

Based on the severity of airflow obstruction, these 144 patients were classified into mild, moderate, severe and very severe airflow obstruction. There were $21(15 \%)$ patients with mild, 34(24\%) patients with moderate, $51(35 \%)$ patients with severe and
38 (26\%)patients with very severe airflow obstruction.

Based on the number of exacerbations and hospitalizations each year and baseline mMRC breathlessness, these 144 patients were grouped into group A, B, C and D. 39(27\%)patients belonged to group A, 31(21\%) to group B, 7(5\%) to group C and 67(47\%) to group D.

Out of these 144 patients, 65 patients had no pulmonary hypertension. 53 had mild $\mathrm{PH}, 12 \mathrm{had}$ moderate $\mathrm{PH}$ and 14 had severe PH. Among the other echo findings, left ventricular diastolic dysfunction (47 patients) was the most common. 7 patients had left ventricular systolic dysfunction and 3 patients had left ventricular hypertrophy.

Pulmonary hypertension and Severity of air flow obstruction

All patients with mild airflow obstruction and most of the patients with moderate airflow obstruction had no PH. Most of the patients with severe and very severe airflow obstruction had PH.

Pulmonary hypertension and groups: Most of the patients belonging to groups $\mathrm{A}$ and $\mathrm{C}$ had no $\mathrm{PH}$. Majority of the group B and group D patients had $\mathrm{PH}$.

ECG changes and Echocardiographic findings:

Even though the ECG was normal a significant proportion of patients with a normal ECG also had PH on echocardiography.

Pulmonary hypertension and number of exacerbations: Patients with $\mathrm{PH}$ had more exacerbations than patients without $\mathrm{PH}$.

CorPulmonale and number of exacerbations:

Patients with corpulmonale had more exacerbations (median 2.5) than patients without corpulmonale.

Pulmonary Hypertension in frequent exacerbators: Most of the frequent exacerbators had PH 
Table: 1 Variables

\begin{tabular}{|l|c|c|}
\hline SEX & & \\
\hline male & 120 & $83 \%$ \\
\hline female & 24 & $17 \%$ \\
\hline GOLD STAGING & & \\
\hline mild & 21 & $15 \%$ \\
\hline moderate & 34 & $24 \%$ \\
\hline severe & 51 & $35 \%$ \\
\hline V,severe & 38 & $26 \%$ \\
\hline GROUPS & & \\
\hline A & 39 & $27 \%$ \\
\hline B & 31 & $21 \%$ \\
\hline C & 7 & $5 \%$ \\
\hline D & 67 & $47 \%$ \\
\hline PULMONARY HT & & \\
\hline NO & 65 & $45 \%$ \\
\hline Mild & 53 & $37 \%$ \\
\hline moderate & 12 & $8 \%$ \\
\hline severe & 14 & $10 \%$ \\
\hline COR PULMONALE & & \\
\hline YES & 18 & $12 \%$ \\
\hline NO & 126 & $88 \%$ \\
\hline
\end{tabular}

Table 2: Pulmonary Hypertension v/s GOLD staging

\begin{tabular}{|l|c|c|c|c|}
\hline \multirow{2}{*}{ PULMONARY } & \multicolumn{4}{|c|}{ SEVERITY OF AIRFLOW OBSTRUCTION } \\
\cline { 2 - 5 } & MILD & MODERATE & SEVERE & VERY SEVERE \\
\hline NO & $100 \%$ & $61.8 \%$ & $29.4 \%$ & $12.3 \%$ \\
\hline MILD & 0 & $38.2 \%$ & $52.9 \%$ & $34.2 \%$ \\
\hline MODERATE & 0 & 0 & $13.7 \%$ & $13.2 \%$ \\
\hline SEVERE & 0 & 0 & $3.9 \%$ & $31.6 \%$ \\
\hline
\end{tabular}

Table 3: Pulmonary Hypertension v/s grouping

\begin{tabular}{|l|c|c|c|c|}
\hline PULMONARY & \multicolumn{4}{|c|}{ GROUPS } \\
\cline { 2 - 5 } & A & B & C & D \\
\hline NO & $92.3 \%$ & $35.5 \%$ & $71.4 \%$ & $19.4 \%$ \\
\hline MILD & $7.7 \%$ & $48.3 \%$ & $28.6 \%$ & $49.3 \%$ \\
\hline MODERATE & 0 & $6.5 \%$ & 0 & $14.9 \%$ \\
\hline SEVERE & 0 & $9.7 \%$ & 0 & $16.4 \%$ \\
\hline
\end{tabular}
$(\mathrm{p}>0.05)$

Figure 1: Association between exacerbations and pulmonary hypertension

Exacerbations

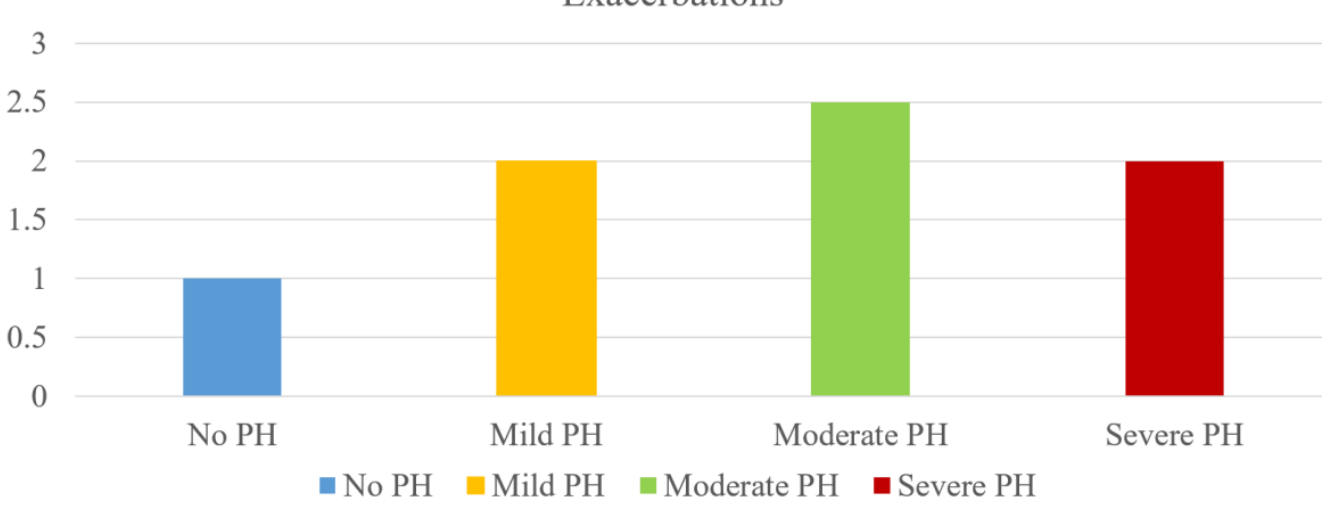

(Kruskal-Wallis Test, $\mathrm{p}<0.001$ ) 
Figure 2: Association between corpulmonale and exacerbations

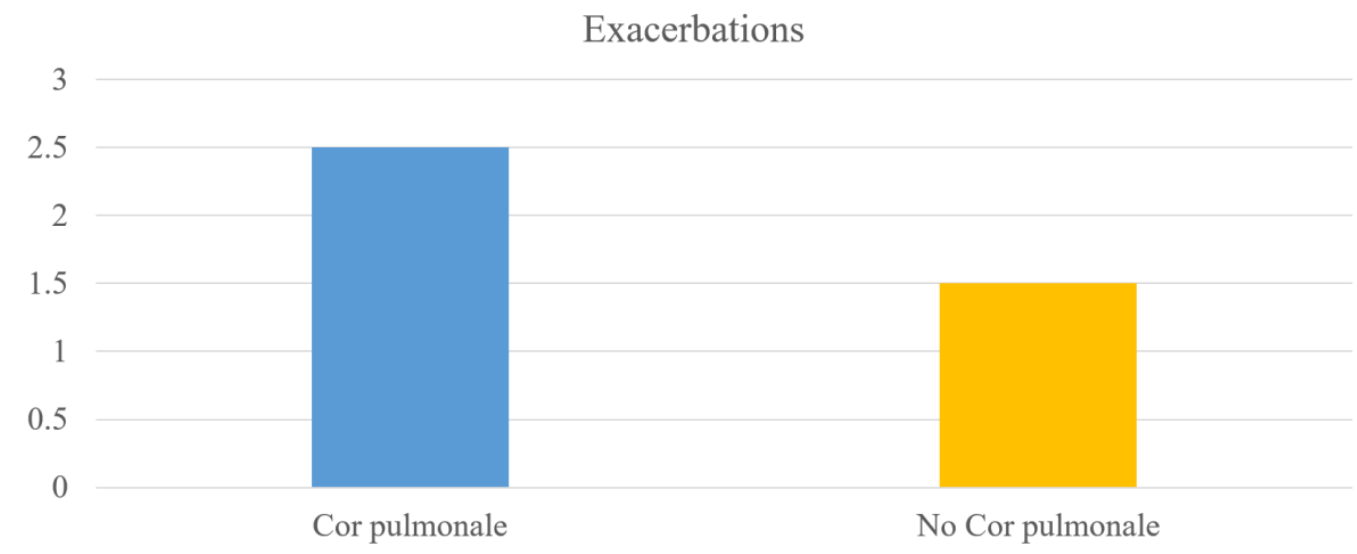

(Mann-Whitney Test, $\mathrm{p}=0.003$

Figure 3: Prevalence of pulmonary hypertension among frequent exacerbators

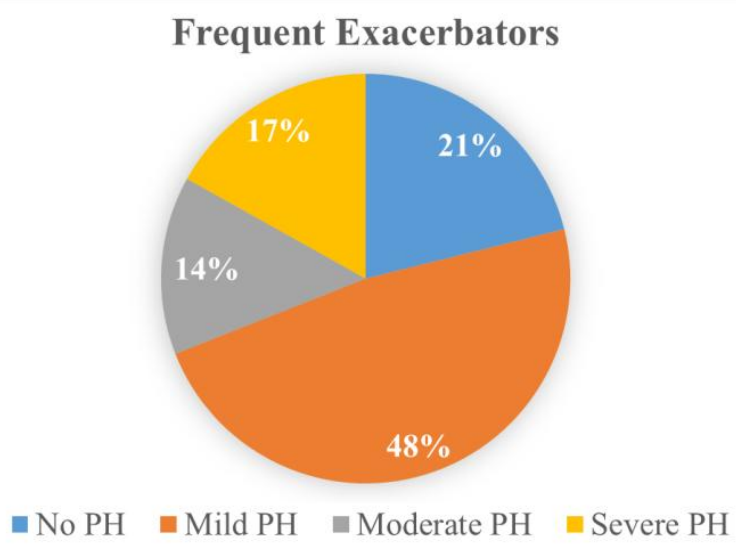

\section{Discussion}

The present study conductedat Pariyaram Medical College assessed the echocardiographic findings in patients with COPD. 144 cases of acute exacerbations, who satisfied the inclusion criteria, were studied from 1/3/2016 to 28/2/2017.

The most common age group was 55-65 years with 69 patients belonging to that age group. Jatav et al also reported maximum patients a similar age group of 60-69 years ${ }^{(15)}$. The mean age in a study done by Shresta et al was $66.1 \pm 10.9$ years ${ }^{16)}$. Freixa et al's study had a mean age group of 67.9 \pm 8.6 years $^{(17)}$. Thus the age group affected was similar with the older age group predominantly involved. Hence COPD is a disease that occurs later in life.

Most of the patients were males (83\%). Jatav et al also reported a similar proportion of male patients $(86 \%)^{(15)}$. Hasan et al reported a higher proportion of male $(88 \%)$ patients $^{(18)}$. The predominance of male patients was due to the higher percentage of smoking among males. Female COPD patients reported exposure to kitchen smoke and other forms of indoor air pollution.

Most of the patients had severe or very severe airflow obstruction on spirometry. A similar scenario can be found in the Jatav et al study ${ }^{(15)}$. Freixa et al study had most of the patients with moderate to severe airflow obstruction. The mean $\mathrm{FEV}_{1}$ in their study was $52.4 \pm 16.2 \%{ }^{(17)}$. Hasan et al had excluded patients with severe and very severe COPD in their study ${ }^{(18)}$. The patients with mild airflow obstruction probably aren't symptomatic enough to seek medical attention. Thus explaining the higher proportion of patients with severe and very severe airflow obstruction. Due to their persistent symptoms and frequent exacerbations, patient belonging to group D were 
more likely to seek medical care. Thus they were the majority of patients who took part in the study. $49 \%$ of the patients had $\geq 2$ exacerbations per year. Out of the 144 patients, 65 patients had normal echo findings. Pulmonary hypertension was the most common echo finding. 18 patients showed evidence of $\mathrm{RV}$ dysfunction along with $\mathrm{PH}$ and hence were diagnosed as having corpulmonale. Among the left ventricular abnormalities, diastolic dysfunction was the most common abnormality. The other abnormalities noted were LVSD and LVH. Mandal et al also reported that diastolic dysfunction was the most common abnormality affecting the LV in patients with $\mathrm{COPD}^{(19)}$. Rawy et al found significant association between LVDD and the severity of airflow obstruction ${ }^{(20)}$. The National emphysema treatment trial, which evaluated 120 patients with severe emphysema, the mean PAP was $26,3 \pm 5.2 \mathrm{mmHg}^{(21)}$. Vizza et al, in their study, evaluated 168 patients listed for lung transplantation. They also obtained similar values of PAP with a $95 \%$ CI of $24.1-25.9$ $\mathrm{mmHg}{ }^{(22)}$. Candidates from lung volume reduction surgery and lung transplantation were investigated by Thabut et al. 36.7\%, 9.8\% and $3.7 \%$ patients had mild, moderate and severe $\mathrm{PH}$ in their study ${ }^{(23)}$. Patients with moderate to severe airway obstruction without hypoxia usually have preserved right ventricular function ${ }^{(24)}$. Vizza et al reported that $59 \%$ of the patients who were evaluated for lung transplant had right ventricular dysfunction. This may be due to the increased severity of airflow obstruction in these patients ${ }^{(22)}$. Thus the findings in our study are in concordance with the other studies.

When pulmonary artery pressure was compared the severity of airflow obstruction was compared with the severity of airflow obstruction, majority of the patients with severe and very severe airflow obstruction had PH. The association, however, was not significant.

Jatav et al found significant association between the RV echo findings and the severity of airflow obstruction $^{(15)}$. Gupta et al also reported that as the severity of COPD increases the prevalence of cardiac dysfunction increases ${ }^{(25)}$. Hasan et al had also come to the conclusion that the echo findings like RVH, TR, PR and PH correlated significantly with the severity of airflow obstruction ${ }^{(18)}$. Thus the findings are in concordance with the other studies.

When the association between $\mathrm{PH}$ and the groups of COPD were analysed, we arrived at the conclusion that patients that fell under groups B and D had a majority of patients with $\mathrm{PH}$. These are the patients with baseline mMRC dyspnea of $\geq 2$. Hence, $\mathrm{PH}$ can have a significant influence on the quality of life of patients with COPD.

No correlation was found between ECG changes and the findings on echocardiography. Many patients with a normal ECG also were found to have $\mathrm{PH}$ on echo. Hasan et al also reported no correlation between ECG findings such as ppulmonale, RVH, RBBB with the echo findings $^{(18)}$.

We also analyzed the association between the number of exacerbations and PH. Patients with PH had more exacerbations than patients with normal echo findings. The correlation was significant. The presence or absence of corpulmonale also showed significant association with the number of exacerbations. Majority of the frequent exacerbators also had $\mathrm{PH}$. Chaouat et al had stated that the presence of $\mathrm{PH}$ is associated with an increased risk of exacerbation and decreased survival. Frequent exacerbations can also result in a decline in pulmonary function which can in turn worsen $\mathrm{PH}^{(21)}$. Hence our results corroborated with the available literature.

\section{Conclusion}

COPD is associated with numerous cardiovascular co morbidities in the North Malabar area of Kerala. . Patients with pulmonary hypertension are more prone to exacerbations. The early diagnosis and initiation of treatment of PH like LTOT could help reduce the morbidity and mortality associated with COPD. Thus, treatment of cardiac co morbidities should also be included as an essential component of treatment of COPD patients along 
with bronchodilators and pulmonary rehabilitation. Patients with $\mathrm{PH}$ should also be monitored closely and treated intensely to prevent recurrent exacerbations and reduce mortality.

\section{Ethical Consideration}

Informed consent was taken from each individual and there were no associated harm to them during the study. There were no major ethical issues involved as no invasive procedures were performed on the patient as a part of the study. All of the above said investigations mentioned were done as a part of routine work up. This study didn't have financial support from any source and the study didn't cause any additional financial burden to the patient

\section{References}

1. Barnes P, Celli B. Systemic manifestations and comorbidities of COPD. Eur Respir J. 2009;33(5):1165-85

2. Agusti A, Edwards L, Rennard S. Evaluation of COPD Longitudinally to Identify Predictive Surrogative Endpoints (ECLIPSE) Investigators. Persistent systemic inflammation is associated with poor clinical outcomes in COPD: a novel phenotype. PLoS One. 2012;7(5):e37483.

3. Corsonella A, Incalzi RA, Pistelli R, C.Pedone, Bustacchini S, Lattanzio F. Comorbidities of chronic obstructive pulmonary disease. Curr Opin Pulm Med. 2011;17(1):s21-8.

4. Restrepo C, Tapson V. Pulmonary hypertension and cor pulmonale. In: Textbook of cardiovascular medicine. 1st ed. Lippincott-Raven; 1998. p. 707-25.

5. Kessler R, Faller M, Fourgaut G, Mennecier B, Weitzenblum E. Predictivfactors for hospitalisation for acurte exacerbation in a series of 64 patients with chronic obstructive pulmonary disease. Am J Respir Crit Care Med. 1999;159:158-64.

6. Daniels L, Krummen D, Blanchard D.
Echocardiography in pulmonary vascular disease. Eur Respir J. 2006;28:1245-57

7. York P, Popp R. Non invasive estimation of right ventricular systolic pressure by Doppler ultrasound in patients with tricuspid regurgitation. Circulation. 1984;70:657-62.

8. Tramarin R, Torbicki A, Marchandise B, Laaban J, Morpurgo M. Doppler echocardiographic evaluation of pulmonary artery pressure in chronic obstructive pulmonary disease. A multicentre study. Eur Heart J.1991;12:103-11.

9. Krishnan R, Srihari B. A study on the severity of right ventricular dysfunction in chronic obstructive pulmonary disease patients. Am J Sci Med Res. 2015;1( 1):112-9

10. Higgins M, Keller J, Landis J. Collaborative assessment of the validity of the Tecumseh index of risk. Am Rev Respir Dis. 1984;130(3):380-5.

11. Short P, Lipworth S, Elder D, Schembri S, Lipworth B. Effect of beta blockers in the treatment of chronic obstructive pulmonary disease: a retrospective cohort study. Br Med J. 2011;342:d2549.

12. Hawkins N, Petrie M, Macdonald M. Heart failure and chronic obstructive pulmonary disease the quandry of betblockers and beta-agonist. J Am Coll Cardiol. 2011;57(21):123-9.

13. Global Initiative of Obstructve Lung Diseases. 2017

14. Chemla D, Castelain V, Humbert M, Simonneau J, Lecarpentier Y, Herve P. New formula for predicting mean pulmonary artery pressure using systolic pulmonary artery pressure. Chest. 2000;126:1313-7.

15. Jatav VS, Meena SR, Jelia S, Jain $P$, Ajmera D, Agarwal V, et al. Echocardiographic findings in chronic obstructive pulmonary disease and 
correlation of right ventricular dysfunction with disease severity. Int $\mathbf{J}$ Adv Med. 2017;4(2):476-80

16. Shresta B, Dhungel S, Chokhani R. Echocardiography based cardiac evaluation in the patients suffering from chronic obstructive pulmonary disease. Nepal Med Coll J. 2009;11(1):14-8

17. Freixa X, Portillo K, Pare C, GarciaAymerich J, Gomez FP, Benet M, et al. Echocardiographic abnormalities in patients with COPD at their first hospital admission. Eur Respir J. 2013;41:784-91

18. Hasan A, Ashraf M. U, Naaz S, Bhargava R, Ashraf J. A study of clinical and echocardiographic profile of patients of chronic obstructive pulmonary disease helping in early diagnosis of cor pulmonale. Int $\mathrm{J}$ Enhanc Res Med Dent Care. 2014;1(1):5-8

19. Mandal S, Chatterjee S, Mandal D, Mitra $\mathrm{R}, \mathrm{S} \mathrm{C}$ M. Left Ventricular Function in Copd Patients- Its Clinical and Echocardiographic Evaluation. J Evol Med Dent Sci [Internet]. 2017;6(31):2512-7. Available from: https://www.jemds.com/data_pdf/1_Saroj Mandal-.pdf

20. Rawy AM, Fathalla D. Left ventricular diastolic dysfunction in patients with chronic obstructive pulmonary disease (COPD), prevalence and association with disease severity: Using tissue Doppler study. Egypt J Chest Dis Tuberc [Internet]. 2015;64(4):785-92. Available from: http://dx.doi.org/10.1016/j.ejcdt.2015.06.0 10

21. Chaouat A, Naeije R, Weitzenblum E. Pulmonary hypertension in COPD. Eur Respir J. 2008;32:1371-85
22. Vizza C, Lynch J, Ochoa L, Richardson G, Trulock E. Right and left ventricular dysfunction in patients with severe pulmonary disease. Chest. 1998;113:57683.

23. Thabut G, Dauriat G, Stern J. Pulmonary hemodynamics in advanced COPD candidates for lung volume reduction suregry or lung transplantation. Chest. 2005;127:1531-6.

24. Vonk-Noordegraaf A, Marcus J, Holverda S, Roseboom B, Postmus P. Early changes of cardiac structure and function in COPD patients with mild hypoxemia. Chest. 2005;127:1289-95

25. Gupta NK, Agrawal RK, Srivastav AB, Ved ML. Echocardiographic evaluation of heart in chronic obstructive pulmonary disease patient and its co-relation with the severity of disease. Lung India [Internet]. 2011 Apr [cited 2017 Nov 7];28(2):105-9. Available from: http://www.ncbi.nlm.nih.gov/pubmed/217 12919. 